\title{
Exaltar la madre
}

\author{
La tía Tula | Miguel Picazo | 1964
}

Amanda Goya*

ELP - Madrid, Asociación Mundial de Psicoanálisis

Recibido: 25 de abril 2017; aceptado: 25 de junio 2017

\section{Resumen}

El presente texto es un análisis acerca de la posición materna, a partir de la película La tía Tula (Picazo, 1964), film elaborado en base a la novela del escritor español Miguel de Unamuno. Tal como la autora lo plantea, mujer y madre pueden coexistir en diferentes proporciones en cada mujer o bien presentarse como excluyentes, tanto en la época freudiana como en la actualidad. ¿Estaremos ante un nuevo síntoma de la declinación de la función paterna de la que tanto hablamos los psicoanalistas lacanianos? Desde nuestra práctica del psicoanálisis no dejamos de tropezarnos todos los días con fenómenos clínicos que ponen de manifiesto las dificultades que supone para un sujeto un apego excesivo a las figuras parentales, a la madre en particular.

Palabras clave: madre $\mid$ mujer $\mid$ declinación de función paterna $\mid$ deseo $\mid$ goce

Praising the mother

\begin{abstract}
The present text is an analysis about the maternal position, from the film La tía Tula (Picazo, 1964), a film based on the novel by the Spanish writer Miguel de Unamuno. As the author puts it, woman and mother can coexist in different proportions in each woman or present themselves as excluding, both in the Freudian times and nowadays. Are we in front of a new symptom of the declination of father function? From our psychoanalytic practice we stumble every day upon clinical phenomena that show us how difficult is for a subject an excessive attachment to his parents, particularly to the mother.
\end{abstract}

Keywords: mother | woman | Decline of paternal function | desire | jouissance

Si Freud se interrogó: “¿Qué quiere la mujer?”, no se formuló sin embargo la pregunta por lo que la madre quiere, porque la madre... ella sí lo sabe, quiere hijos, y a veces también al hombre que se los da, aunque en ocasiones él sea solo un instrumento para tenerlos.

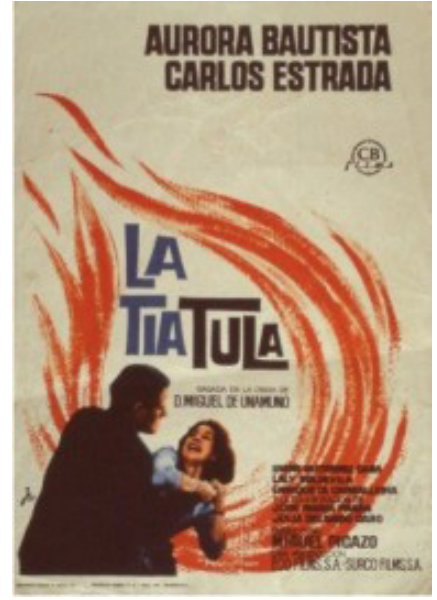

La maternidad es por excelencia una solución a la cuestión femenina en el registro del tener, diferente de la dimensión del ser, pero que no la excluye. Mujer y Madre son dos destinos posibles que pueden coexistir en proporciones muy diferentes entre una mujer y otra, o por el contrario pueden llegar a divergir presentándose incluso como excluyentes.

Es el caso de la creación literaria del genial Miguel de Unamuno, escritor, filósofo, poeta, destacado miembro de la generación del 98, a la vez que hombre comprometido con la República, con el personaje de la tía Tula, la última de sus novelas publicada en 1921, llevada a la pantalla por el director Miguel Picazo en los años 60, y representada por Aurora Batista en una de sus mejores interpretaciones como actriz y el argentino Carlos Estrada. Gertrudis, apodada Tula, es una mujer en la que conviven un potentísimo anhelo de maternidad, junto a una férrea represión del deseo sexual y de su posición de

*agoyapinto@gmail.com 
objeto de deseo de un hombre, en su caso, su cuñado, el marido de su hermana Rosa.

La película, excelente por cierto, difiere algo de la novela, porque no abarca toda la historia que Unamuno relata, sino solo una parte, $y$ aunque se puede decir que el mensaje es el mismo, el libro permite observar mucho mejor la importancia del triángulo que forman las dos hermanas huérfanas, Rosa y Gertrudis, con el hombre, Ramiro.

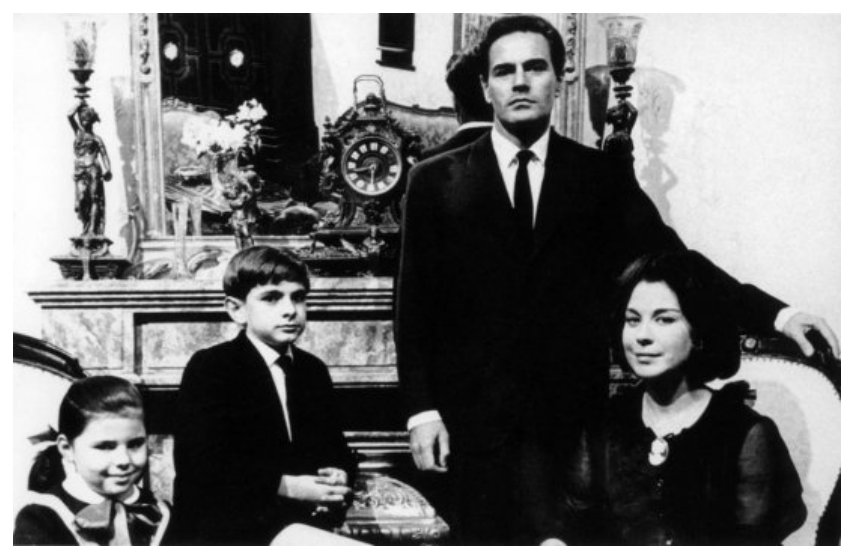

En este triángulo amoroso es Tula quien maneja los hilos de la trama. Leamos cómo describe el autor a las jóvenes hermanas en la primera página del relato, descripción de una gran belleza:

Bien miradas y de cerca, aún despertaba más Gertrudis el ansia de goce. Mientras su hermana Rosa abría espléndidamente a todo viento y a toda luz la flor de su encarnadura, ella era como un cofre cerrado y sellado en el que se adivinaba un tesoro de ternuras y delicias secretas (De Unamuno, 1921 [2001]).

Rápidamente Tula empuja al matrimonio a Rosa y a Ramiro para que tengan hijos y así poder ocuparse ella misma de su crianza. La muerte de Rosa a consecuencia de su tercer parto le permite colocarse definitivamente en el sitio de la madre adoptiva de esos niños, sitio que no abandonará hasta el final de sus días, pero con el mismo tesón rechazará sin vacilar el lugar de mujer en el deseo de su cuñado. Identificada a la posición de madre-virgen, aquella que es capaz de concebir sin la intervención del varón, Tula se acantona en un rechazo al deseo y al goce sexual con su cuñado hasta que éste muere, y solo en la posterior agonía de Ramiro, cuando tiene la certeza de haberlo perdido para siempre, la virginal Gertrudis reconoce, en la fugacidad de unos instantes, su escondido deseo de mujer por ese hombre, deseo que entierra para siempre junto al cadáver de Ramiro que muere entre sus brazos.

Podría parecer que posición semejante solo habríamos de hallarla en una época que se sitúa en las antípodas de la nuestra en lo relativo a los usos y costumbres de la sexualidad y a la crianza de los niños, la misma época en la que Freud supo leer el sentido sexual de las representaciones inconscientes.

Sin embargo, y salvando las distancias, hay ciertas prácticas que en la actualidad se recomiendan a las madres en lo tocante a la relación con el bebé, su alimentación, sus hábitos con el sueño, etc., que privilegian a la madre a despecho de la mujer, desde el supuesto de que hay que fomentar la cercanía entre la madre y el niño a cualquier precio. Son prácticas que suponen una idealización tan extrema de la maternidad que la hacen confinar con un imperativo del superyó. Hay quienes, dejándose llevar por un fanatismo por la lactancia con el pecho materno, satanizan a las mujeres que por algún motivo particular optan por el biberón.

En algunos casos la fecundación in vitro en mujeres sin pareja masculina se inscribe también en esta línea. Véase también la edulcorada trilogía del pediatra Carlos González, bestseller en el género: Bésame mucho; Un regalo para toda la vida; Mi niño no me come, recopilados los tres en un volumen titulado: Comer, amar, mamar (González, 2013).

Allí encontrarán un compendio de recetas para fomentar el apego hasta la saciedad de los niños a sus padres, que parte de la exaltación de una supuesta educación natural, que puede llegar al extremo de una prolongación de la lactancia hasta unas edades en que los niños asisten ya al parvulario.

¿Estaremos ante un nuevo síntoma de la declinación de la función paterna de la que tanto hablamos los psicoanalistas lacanianos?

La respuesta es sin duda afirmativa. Desde nuestra práctica del psicoanálisis no dejamos de tropezarnos todos los días con fenómenos clínicos que ponen de manifiesto las dificultades que supone para un sujeto un apego excesivo a las figuras parentales, a la madre en particular.

Las Gertrudis de nuestros días no necesitan apelar a la religión, como en los tiempos de Unamuno, para consagrarse obsesivamente a la maternidad. Con el auxilio de la Psicología les alcanza.

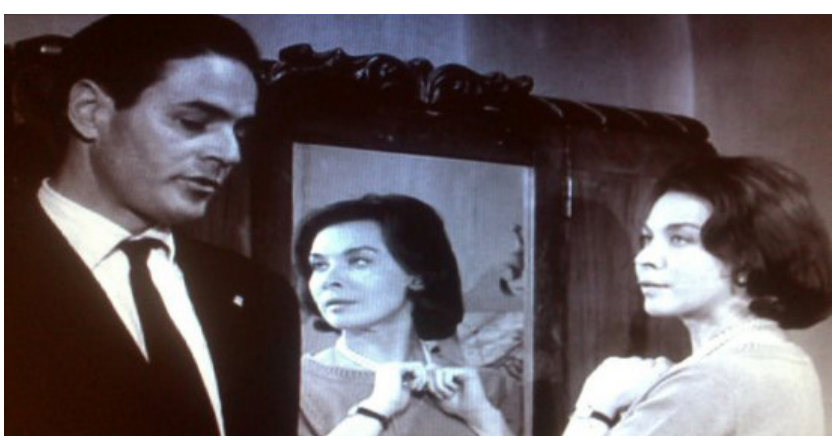




\section{Referencias}

Freud, S. (1931 [1976])). Sobre la sexualidad femenina. Obras Completas. Vol. XXI. Buenos Aires: Amorrortu.

De Unamuno, M. (1921 [2001]). La Tía Tula. Madrid: Editorial Espasa.

Lacan, J., (1972-1973 [2007]) “Aún” en El Seminario de Jacques Lacan. Libro 20. Buenos Aires: Paidós. 